\title{
Mobilidade e identidade estudantil em con- texto transnacional: uma análise dos relatos de ex-alunos do programa de intercâmbio PEC-G
}

Michele Aparecida de Souza ${ }^{1}$

\section{Resumo}

O Programa Estudante Convênio - Graduação (PEC-G) seleciona alunos de outros países para estudar em universidades brasileiras. Essa pesquisa analisa os relatos das experiências que esses ex-alunos tiveram no Brasil. Foi observado quais memórias e narrativas eles selecionaram para construir o significado desta experiência de vida e de aprendizagem em outro país. A narrativa faz parte de um conjunto de memórias que um sujeito seleciona no momento em que descreve uma trajetória de vida. A memória contribui na formação de identidades, pois as memórias selecionadas e as esquecidas fazem parte de uma interpretação e construção do "eu". No momento em que um sujeito narra sua suposta trajetória, ele vai pinçar as memórias que quer que sejam destacadas e fará isso com a finalidade de justificar a maneira como ele enxerga a si mesmo em determinados momentos e situações. O estudo foi feito por meio da pesquisa documental, levantamento bibliográfico e análise dos relatos de vida publicados no site oficial do programa PEC-G no Brasil. Os relatos selecionados foram de alunos que estudaram no Brasil entre as décadas de 1970 e 1980, foram escolhidos os alunos desse período para dar ênfase a esse estudo, pois as memórias desses alunos já estão solidificadas em relação à experiência que obtiveram no Brasil o que contempla o estudo a seguir.

Palavras-chave: Migração; Identidade; Memória; PEC-G.

\footnotetext{
${ }^{1}$ Bacharel em Ciências Sociais pela Universidade Federal de São Paulo - UNIFESP. E-mail: mimichele21@gmail.com
} 


\begin{abstract}
PEC-G selects students from other countries to have the opportunity to study in Brazilian universities. This research aims to study the program's former students' reports and to analyze the experiences they had as immigrant students in Brazil. It was observed which memories and narratives they selected to describe the meaning of this experience to their life stories. The narrative is part of a set of memories that a person selects when describing a life trajectory. Memory contributes to the formation of identities as the selected memories and the forgotten ones are part of an interpretation for the construction of the "self". The moment an individual narrates his supposed trajectory, he will pick up the memories that he wants to be highlighted and will do so in order to justify the way he sees himself in certain moments and situations. The study was made by the use of documental and bibliographical research and analysis of the life stories published on the official website of the PEC-G program in Brazil. The selected reports were from students who studied in Brazil between the 1970s and 1980s, students from that period were chosen to emphasize this study as these students memories are already solidified in relation to the experience they obtained in Brazil, which contemplates the following study.
\end{abstract}

Keywords: Migration; Identity; Memory; PEC-G.

\title{
Introdução
}

Esse artigo foi produzido a partir de uma pesquisa de um trabalho de conclusão de curso para obtenção do grau de bacharelado em Ciências Sociais. Para realização dessa pesquisa foram selecionados vídeos de ex intercambistas que obtiveram sua formação universitária no Brasil através do Programa Estudantes-Convênio de Graduação. Esses vídeos estão disponíveis na plataforma online do respectivo programa.

O programa PEC-G (Programa Estudantes-Convênio de Graduação) foi desenvolvido pelos Ministérios das Relações Exteriores e da Educação em parceria com universidades públicas e particulares com a finalidade de oferecer uma formação superior a jovens de países em vias de desenvolvimento. De acordo com o Portal do MEC, o PEC-G oferece essa oportunidade a países com os quais o Brasil mantém acordos educacionais e culturais, selecionando estrangeiros preferencialmente entre dezoito a vinte e cinco anos. Algumas das condições para esses alunos estudarem no Brasil é que eles tenham condições de se manter em termos econômicos, e devem retornar ao seu país de origem ao término do curso. Eles também não podem trabalhar no Brasil. Os países que mais enviam estudantes ao Brasil através do programa são Cabo Verde e Guiné Bissau. 
De acordo com as informações da plataforma online da Divisão de Temas Educacionais $^{2}$, esse programa foi implementado na década de 1960 porque houve um aumento no fluxo de estudantes imigrantes no Brasil cursando o ensino superior. Por esse motivo, o governo criou um programa para regularizar e amparar esses estudantes estrangeiros nas instituições brasileiras de ensino superior. Criou-se, em 1965, o primeiro protocolo do Programa Estudantes-Convênio de Graduação (PEC-G). Este foi concebido devido à necessidade de unificar as condições do intercâmbio estudantil e de garantir tratamento semelhante aos estudantes por parte das universidades. Desde 2013, o Programa é regido pelo Decreto Presidencial $n^{\circ}$ 7.948. Atualmente, o PEC-G conta com cinquenta e nove países participantes, sendo vinte e cinco da África, vinte e cinco das Américas e nove da Ásia. Desde o ano 2000, foram selecionados mais de nove mil estudantes. A África é o continente com o maior número de estudantes: 76\% são de origem africana. Entre as nações africanas participantes, destacam-se Cabo Verde, Guiné-Bissau e Angola, como pode ser visto pela tabela a seguir, produzida pelo Divisão de Temas Educacionais:

Tabela 1 - Estudantes selecionados pelo PEC-G na África entre 2000 e 2019

\begin{tabular}{|c|c|c|c|c|c|c|c|c|c|c|c|c|c|c|c|c|c|c|c|c|c|}
\hline PAis & 2000 & 2001 & 2002 & 2003 & 2004 & 2005 & 2006 & 2007 & 2008 & 2009 & 2010 & 2011 & 2012 & 2013 & 2014 & 2015 & 2016 & 2017 & 2018 & 2019 & TOTAL \\
\hline África do Sul & & & & & & & & & & & & & & & & & & 1 & 1 & & 2 \\
\hline Angola & 3 & 21 & 29 & 23 & 33 & 11 & 31 & 28 & 91 & 68 & 48 & 83 & 63 & 53 & 59 & 77 & 7 & 11 & 12 & 2 & 753 \\
\hline Argélia & & & & & & & & & & & & & & & & 2 & & & & & 2 \\
\hline Benin & & & & & & & & & 11 & 5 & 7 & 19 & 39 & 37 & 73 & 48 & 40 & 71 & 44 & 93 & 487 \\
\hline Cabo Verde & 117 & 65 & 227 & 263 & 192 & 230 & 314 & 265 & 381 & 206 & 133 & 74 & 155 & 88 & 104 & 119 & 64 & 62 & 58 & 52 & 3169 \\
\hline Camarões & & & 1 & & & & & 2 & 1 & & 3 & 6 & 3 & 9 & 7 & 3 & 5 & 7 & 2 & 4 & 53 \\
\hline Costa do Marfim & & & & 1 & 1 & & & 3 & 1 & & & & 1 & 4 & 9 & 4 & 5 & 5 & 8 & 15 & 57 \\
\hline Gabão & & 11 & & 2 & 1 & 1 & 3 & 4 & & & & & & & 3 & 4 & 3 & 2 & 10 & 16 & 60 \\
\hline Gana & 2 & 3 & 7 & 9 & 11 & 6 & 3 & 3 & 6 & & 1 & 1 & & 7 & 26 & 23 & 36 & 65 & 58 & 19 & 286 \\
\hline Guiné-Bissau & 36 & 88 & 111 & 97 & 58 & 186 & 159 & 19 & 133 & 181 & 95 & 55 & 118 & & & & 7 & 15 & 33 & 25 & 1416 \\
\hline Guiné Equatorial & & & & & & & & & & & & & & & & & & & & 27 & 27 \\
\hline Marrocos & & & & & & & & & & & & & & & & & & 1 & & 2 & 3 \\
\hline Mali & & & & & & & 2 & & & & & & & & & & & & 1 & & 3 \\
\hline Moçambique & 12 & 13 & 27 & 21 & 26 & 27 & 13 & 9 & 4 & 4 & 9 & 7 & 8 & 13 & 13 & 9 & 1 & 3 & 2 & 8 & 229 \\
\hline Namibia & 1 & 1 & & & & & & & & & & & & & & 6 & 65 & & 1 & & 74 \\
\hline Nigéria & 9 & 6 & 7 & 11 & 14 & 27 & 19 & 22 & 32 & & & 12 & 1 & 2 & 6 & 2 & & 2 & 1 & 4 & 177 \\
\hline Quênia & & 4 & 14 & 14 & 11 & 12 & 5 & & 6 & 3 & 3 & 3 & & 2 & & 4 & 3 & 4 & 1 & & 89 \\
\hline República Dem. do Congo & & & & & & & & 9 & 106 & 46 & 78 & 92 & 28 & 19 & 12 & 25 & 29 & 46 & 37 & 25 & 552 \\
\hline República do Congo & & & & & & & & & & & & & 4 & 6 & 4 & 2 & 4 & 6 & & 30 & 56 \\
\hline São Tomé e Príncipe & & & 24 & & 47 & 147 & 35 & 13 & 12 & 4 & 6 & 19 & 12 & 3 & 19 & 17 & 9 & 12 & 2 & 7 & 388 \\
\hline Senegal & 7 & 2 & 4 & 1 & 1 & 3 & 5 & 1 & & & & 1 & 1 & 4 & 1 & 6 & 3 & 10 & 7 & 7 & 64 \\
\hline Togo & & & & & & & & & & & & 4 & 11 & 8 & 3 & 6 & 6 & 2 & 3 & 1 & 44 \\
\hline TOTAL & 187 & 214 & 451 & \begin{tabular}{|l|l|l|l}
442 & $x$ \\
\end{tabular} & 395 & 650 & 589 & 378 & 784 & 517 & 383 & 376 & 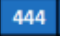 & 255 & 339 & 357 & 287 & 325 & 281 & 337 & 7991 \\
\hline
\end{tabular}

Fonte: Divisão de Assuntos Educacionais/Introdução ${ }^{3}$

\footnotetext{
2 http://www.dce.mre.gov.br/PEC/G/historico/legislacao_anterior.php

${ }^{3}$ http://www.dce.mre.gov.br/PEC/G/historico/introducao.php
} 
Esta pesquisa foi desenvolvida, a partir da análise dos relatos de ex-alunos que estudaram no Brasil através do PEC-G, com o intuito de entender de que maneira essas pessoas enxergam o seu passado a partir da perspectiva do seu presente, alicerçados nas memórias selecionadas por meio da experiência de intercâmbio estudantil e cultural. O objetivo deste estudo é examinar as memórias selecionadas pelos ex-estudantes que compõem os relatos presentes em suas entrevistas. Os ex-alunos do PEC-G narraram a importância de estudar no Brasil e destacam as percepções identitárias que eles experenciaram ao comparar o Brasil com seus países de origem.

Os relatos usados como base dos estudos encontram-se em formato de vídeos e estão disponibilizados no Portal do PEC-G. Na entrevista esses ex-alunos são convidados a relataram suas experiências como estudantes estrangeiros no Brasil. O entrevistador somente faz uma ou duas perguntas no começo das entrevistas e o entrevistado expõe a sua história.

Eles narram essas histórias olhando para um passado que faz mais de trinta ou quarenta anos. Portanto, esses alunos vão olhar de forma distante para esse passado e "costurando" com a pessoa que eles se veem no momento atual. Memórias serão selecionadas, memórias foram esquecidas e muitas foram omitidas. As selecionadas irão dar sentido na trajetória a partir de uma modelagem dessas lembranças para elucidar o momento atual de vida desses ex alunos. Por se tratar de um programa estatal, foram selecionados os vídeos com as melhores experiências vividas aqui no Brasil e de pessoas que obtiveram sucesso profissional em seu país de origem. Dentre todos os vídeos que se encontram no portal, os selecionados para análise foram dos alunos que vieram estudar no Brasil entre as décadas de 70 e 80 e as entrevistas foram colhidas no ano de 2017.

Nas entrevistas, esses ex-alunos foram convidados a relatarem suas experiências como estudantes estrangeiros no Brasil. Em seus relatos, memórias foram selecionadas, memórias foram esquecidas e muitas foram omitidas. Os relatos de vida desses ex-alunos serão analisados por meio das teorias de Gabriele Rosenthal (História de vida vivenciada e história de vida narrada, 2014) e Joël Candau (Memória e Identidade, 2011), que discutem a construção das memórias através das narrativas de vida, estritamente ligadas às memórias selecionadas pelos indivíduos no tempo presente.

CANDAU (2011) sustenta que as memórias não podem ser recuperadas em sua integridade. Para ele, o sujeito seleciona e readequa tais memórias de acordo com a situação 
presente e projeta uma ideia de futuro. O que foi armazenado e o que foi descartado possivelmente será utilizado com a finalidade de moldar a nossa identidade:

A memória, ao mesmo tempo em que nos modela, é também por nós modelada. Isso resume perfeitamente a dialética da memória e da identidade que se conjugam, se nutrem mutuamente e se apoiam uma na outra para produzir uma trajetória de vida, uma história, um mito, uma narrativa. E, ao final, resta apenas o esquecimento. (CANDAU, 2011, p.16)

O que foi esquecido também deve ser considerado na análise, segundo o mesmo autor, a partir do que se oculta (ou do que é esquecido), irrompe em um narrativa, por isso é preciso analisar esse esquecimento não como uma debilidade e sim como um artifício inconsciente que contempla a narrativa.

ROSENTHAL (2014) analisa processo narrativo no qual questiona o que é realmente vivido e, dessa vivência, o que é selecionado para ser narrado. Ela afirma que, a partir da percepção de que as vivências narradas se referem às memórias do processo narrativo, ressaltando que as lembranças não são constituídas de memórias armazenadas ou fixadas, pelo contrário: no momento da narração o indivíduo faz um julgamento retrospectivo acerca do passado e gera um pretérito específico em cada caso.

\section{Mobilidade estudantil, memória e identidade}

As narrativas que os ex-alunos construíram no momento (no ano de 2017) em que a entrevista foi colhida, elucida a condição atual de suas vidas, nesses casos, reflete sobre a vida profissional dos alunos, uma vez que o intercâmbio foi realizado para formação profissional desses indivíduos. A narrativa construída e as memórias selecionadas buscam revelar o profissional que cada pessoa se tornou e como cada um se vê após décadas de sua experiência migratória. BRUNER (2014, p.109) explica que, por meio da narrativa, "o 'eu'é criado a partir de uma autocontinuidade postural e espaço-temporal que vai de dentro para fora" (grifo nosso), ou seja, a autoconstrução é afetada através de interações com as pessoas e situações vividas, constroem-se histórias que define o sujeito para que esse enfrente as situações que vivenciará. A identidade do indivíduo é nutrida através de conexões. E essa identidade singular é em grande parte derivada das histórias que são narradas com o objetivo de juntar todos os fragmentos. BRUNER (2014, p. 110), afirma que "improvisamos no modo como falamos 
de nós mesmos para nós mesmos; improvisamos no interesse de que o investimento em nosso equilíbrio não se perca" (grifo nosso).

$\mathrm{Na}$ análise da narrativa dos ex-alunos do PEC-G, percebe-se que os relatos dados por eles em relação à participação no programa em questão explicitam como cada um se vê atualmente em termos da carreira profissional. Eles destacam que devem toda conquista profissional à experiência que eles viveram nas universidades brasileiras. Desse modo, percebe-se que as memórias selecionadas para emoldurarem o relato dizem respeito a como esses indivíduos se enxergam a partir da experiência vivida. Pierre Nora (1992) afirma que:

A memória está aberta à dialética da lembrança e do esquecimento, inconsciente de suas deformações sucessivas, vulnerável a todos os usos e manipulações, suscetível de longas latências e de repentinas revitalizações. [...] A memória é um fenômeno sempre atual, um elo vivido no eterno presente, $[. .$.$] alimenta-se de lembranças vagas, telescópicas, globais ou flu-$ tuantes, particulares ou simbólicas, sensível a todas as transferências, cenas, censuras ou projeções. (NORA, 1992, p. 9)

Para a estruturação da identidade, também se usa a memória. As memórias que um indivíduo guarda de suas experiências de vida, modela e também vai sendo modelado adequadamente para construção do “eu”, um ser lógico. É através da memória que se revela a personalidade de um indivíduo. As memórias escolhidas para a construção da identidade irão depender da ideia que o sujeito tem de sí próprio, com base em lembranças de experiências passadas.

Ainda para CANDAU (2011), quando um indivíduo se distancia do passado, há uma abertura de espaço para uma reconstrução complexa de história e ficção: da verdade que pode ser constatada e da verdade estética, ou seja, a verdade que será relatada como a construção de uma obra de arte. A reconstrução tende à aclaração de como se quer que o "eu" seja representado, ou seja, as narrativas de vida consistem em dominar o próprio passado a fim de esmiuçar não o vivido, mas o que se quer que fique do vivido. O narrador ordena os acontecimentos para tornar coerentes os fatos que ele pressupõe significativos no momento da narrativa:

[...] restituições, ajustes, invenções, modificações, simplificações, esquematizações, esquecimentos, censuras, resistências, recusas, "vida sonhada", ancoragens, interpretações e reinterpretações. Estas constituem a trama desse ato de memória que é sempre uma excelente ilustração das estratégias identitárias que operam em toda a narrativa. (CANDAU, 2011, p. 71) 
O autor ainda considera que a apropriação do passado, no que tange à narrativa de vida construída a partir da memória, pode ser observada também na tendência dos indivíduos a memorizar menos os acontecimentos neutros - experiências que não têm relação ou não podem dar nenhum significado ao presente - do que aqueles carregados afetivamente. O mesmo autor também explica que os indivíduos tendem a esquecer mais rapidamente aqueles que são mais desagradáveis do que outros e, com o tempo, vai-se atenuando o lado desagradável de algumas lembranças. Isso é feito através de estratégias, como as omissões. E, ainda que não exista nada de sistemático no princípio do prazer da memória, pode-se considerar que o otimismo memorial prevalece sobre o pessimismo. Há indivíduos que tentam “tirar” uma lição ou algum aprendizado através das experiências julgadas como ruins.

Ao assistir às entrevistas, observa-se que os entrevistados narram suas trajetórias de vida acadêmica minimizando as experiências negativas e, elas são relatadas por meio de uma ressignificação para que haja um entendimento positivo sobre tal fato.

\section{Análise dos depoimentos dos ex-alunos PEC-G}

Na plataforma do PEC-G há fotos e outros depoimentos de alunos que participaram desse programa, a maioria são de homem e de pessoas que ocupam altos cargos em seus países. Há relatos de alunos que realizaram o curso depois dos anos 2000, mas a análise desses alunos não contemplaria essa pesquisa pois esses alunos são muitos novos e com poucas experiências de vida no que tange a carreira profissional e pessoal. A escolha das entrevistas apresentadas aqui nesta pesquisa foi escolhida de alunos que estudaram no Brasil na mesma época, entre as décadas de 1970 e 1980 pois essas pessoas já estão com as memórias mais solidificadas e estruturadas, ou seja, já possuem uma longa trajetória, narrativa de vida e uma grande bagagem de memórias. Também foram selecionados os vídeos com as melhores qualidades de som.

Ana Emília de Barros Sá - da Guiné-Bissau, fez parte da seleção do PEC-G em 1978 e cursou Ciências Sociais na Universidade de São Paulo (USP); foi Conselheira do Ministro de Estado da Função Pública, Reforma do Estado, Trabalho e Segurança Social, de abril de 2013 a junho de 2014, e é a atual Presidente do Instituto da Mulher e da Criança daquele país. 
Em sua trajetória pelo Brasil, Ana destaca que o Brasil é um país que tem uma cultura e uma raiz histórica muito parecida com o seu país de origem. Sua narração destaca vários momentos importantes: quando chegou no Brasil, quando teve um filho no país, o momento de retorno e os feitos profissionais que atingiu através da formação, e os laços criados com o Brasil. A depoente afirma que o Brasil é a sua segunda pátria, para sustentar essa afinidade que teve com os costumes brasileiros, destaco o trecho de memória selecionado para solidificar tal argumento. Ela enaltece a solidariedade que encontrou no Brasil, que faz referência ao povo guineense:

[...] para mim eu considero o Brasil como a minha segunda pátria, no sentido em que eu fui muito jovem para o Brasil, com menos de 20 anos, pronto! Quando lá cheguei, foi um impacto, digamos, [...] pelo contrário, tive um acolhimento favorável, sobretudo da parte das universidades, no aeroporto tive um acolhimento favorável, isso já no primeiro momento, isso me marcou muito positivo, nas relações humanas também foi ótimo [...] essa solidariedade humana que o Brasil tem e que a Guiné-Bissau também tem. (BARROS SÁ, 2017 - Divisão de Temas Educacionais)

Nesse trecho de memória, Ana iguala o Brasil e a Guiné Bissau em termos de acolhimento e solidariedade humana, a partir disso, a depoente identificou as semelhanças culturais entre os dois países. Ao afirmar: "eu considero o Brasil como a minha segunda casa" isso faz com que se identifique com mais de um país em termos de identidade cultural. $\mathrm{Na}$ continuidade de sua entrevista, há outras narrativas que enaltecem tal solidariedade: ela afirma que o avião fez escala em vários estados antes de chegar em São Paulo, mas foi quando chegou no Maranhão, percebeu que sua mala foi extraviada, ficou sem saber o que fazer e um casal de médicos de São Paulo a ajudou a realizar os procedimentos para que recuperasse a mala. O casal a ajudou quando Ana chegou em São Paulo: ficou por dois dias hospedada na casa deles. Isso a impressionou, e a mesma cita que, mesmo sendo uma estranha, esse casal confiou nela e ofereceu a casa deles até que recuperar a mala. No decorrer de sua narrativa, são apontados outros fatos que solidificaram seus laços com o Brasil: ela e o marido - ele também intercambista do programa PEC-G - tiveram um filho no Brasil durante o período que imigraram como estudantes. O filho ficou com sua irmã - também estudante do programa PEC-G - conseguiu um emprego e se estabeleceu no Brasil. Esse filho ficou no país e se formou em medicina; hoje é médico-cirurgião urologista, mora e tem família no Brasil. A irmã da entrevistada/de Ana Emília é professora na Universidade de Direito do Largo São Francisco (USP) em São Paulo. Ana diz que a filha do meio, que é guineense, também estudou no Brasil através do programa PEC-G e formou-se em 
Medicina. Nessa parte da narrativa de Ana, observa-se as memórias selecionadas para estruturar e solidificar a sua identidade afim de estreitar as suas relações com o Brasil, país que considera a sua segunda pátria. Além disso, ela cita que o Brasil e a Guiné-Bissau possuem histórias parecidas no que diz respeito aos dois países terem o mesmo colonizador, Portugal, e falarem a mesma língua.

Segundo HALBWACHS, a reconstrução, seleção, a narrativa de todo indivíduo vai depender do que lhe é contemporâneo, portanto, as lembranças ofereceram/oferecerão uma visão dos acontecimentos passados, em parte transformada pelo presente, ou pela posição que o sujeito ocupa no presente. CANDAU (2011, p. 77) afirma ainda que as experiências e história de vida do sujeito podem ser vista como uma memória que poderá ser remodelada em função das relações com o presente, ou seja, ele os associa o passado e o presente e os torna coerentes "a fim de que possam fundar uma imagem satisfatória de si mesmo" (grifo nosso)

Na narração da Ana Emília, observa-se que a sua identidade com o Brasil se dá com as origens históricas dos dois países, a língua e ao fato de ela ter imigrado para o Brasil muito nova. Além das raízes do Brasil e Guiné-Bissau terem o mesmo colonizador, Ana cita o Brasil como um país-irmão:

[...] a gente teve a opção de três países que a gente quer fazer uma formação superior. Então en coloquei dois países e mais o Brasil, e acabei ficando com o Brasil. Eles escolheram o Brasil, porque também é um país-irmão, não só em termos de lingua, mas também como sabemos, em termos de cultura e em termos de raízes históricas, então para mim foi uma abertura que foi para ampliar meus conbecimentos e também para contribuir para o meu país, e foi nesse âmbito que eu fui para o Brasil em 1978. Por isso que quando eu digo que nós fomos os pioneiros da recuperação. Finais dos anos setenta e a principio dos anos oitenta. Estudei na USP [...], foi lá que eu me formei. Foi uma, digamos que, o Brasil para mim, eu já tinha dito que... foi para mim... eu considero o Brasil como a minha segunda pátria.

[...] Eu acho que o Brasil para mim, ampliou a visão de mundo, em termos sociais, políticos e econômicos. Em termos de relações humanas e em termos de uma integração, em termos de uma interação com outras culturas, porque esse interagir me permitiu fazer novas amizades, ver o ser bumano com outros olhos, e sobretudo, eu fui uma aluna integrada em uma área social, e isso foi um complemento para mim, para ver o mundo de outra forma, com outros olhos [...]. Eu agradeço bastante, nesse âmbito, nos tínhamos uma boa base aqui (Guiné-Bissau), nós fizemos uma escola aqui à nivel de Portugal com professores portugueses, nos tivemos uma base muito boa. Então quando chegamos lá (Brasil) eles tinham um bom conceito de estudantes guineenses e cabo-verdianos, porque nós fomos para estudar e estudávamos [...]. (BARROS SÁ, 2017 Divisão de Temas Educacionais) 
Sua narrativa explana uma memória que elucida no próprio "eu” as bases de uma experiência coletiva. Quando recorda sobre a sua formação do ensino básico no qual ela, outros guineenses e cabo-verdianos tiveram no país de origem acabou colaborando para que ela e os outros intercambistas da Guiné-Bissau e Cabo Verde tivessem um excelente rendimento universitário no Brasil. Nessa narrativa foi dado um significado a respeito da sua vida universitária, isso sugere uma "memória coletiva que vai alimentar o sentimento de identidade, que dispõe de bases sólidas, que vai reforçar a crença em uma origem ou uma história comum ao grupo" (grifo nosso), como explica CANDAU (2011, p. 77).

Em outro período da narrativa, Ana também descreve outro momento que faz referência a uma memória coletiva:

[...]não quero me gabar, nós estudantes no Brasil, tínhamos uma aceitação muito grande em termos da nossa competência [...], nós sempre fomos os preferidos porque nós engajávamos e nós obtivemos resultados positivos em termos no nosso trabalbo. E eu digo que o Brasil é um país irmão, e continua a ser, o Brasil tem uma cooperação com a Guiné-Bissau e continua a fortificar essa relação por longos anos, porque até agora, eu não sei os dados, mas eu sei que... que... eu não sei se chegamos a três mil ou mais (estudantes), desde a minha época até agora, e eu penso que o Brasil continuou e continua a dar o seu apoio a Guiné-Bissau, não só em termos de educação, mas também penso em termos de saúde, porque eu tive a oportunidade de abrir.. de ser também uma das pioneiras da criação da Secretária Nacional de Luta Contra a SID $A^{4}$, então fiz. um concurso a nivel da saúde, era um projeto financiado pelo banco mundial e eu fui selecionada para trabalhar como responsável pelo aconselhamento, teste e apoio psicológico [...] os nossos doentes eram soropositivos e os medicamentos foram doados pelo Brasil [...] (BARROS SÁ, 2017 - Divisão de Temas Educacionais).

ROSENTHAL (2014) afirma que, quando nos envolvemos com uma narração espontânea e com um processo de narração de histórias, via de regra, nos envolvemos com um fluxo recordativo, isso possibilita uma proximidade muito mais intensa com o passado vivenciado naquela época. A construção dessa narrativa do passado, que se costura com os fatos presentes, cria uma narrativa que conecta tais fatos, com as conquistas do presente. De acordo com o site do PEC-G, Ana Emília é Presidente do Instituto da Mulher e da Criança na Guiné-Bissau. Na observação empírica de toda a narrativa, faz-se um apelo positivo da sua trajetória com vistas aos elementos conquistados no presente. CANDAU (2011) esclarece que a integralização da existência do sujeito pode ser vista como uma memória modelada pelas lembranças imediatas e acessos à memória para que essas façam

${ }^{4}$ Síndrome da Imunodeficiência Humana Adquirida - HIV. 
relações com o presente. A memória organiza e as lembranças deixadas pelo passado, quando selecionadas, unificadas e estruturadas de forma coerente formam uma imagem satisfatória de si mesmo. "Se existe sempre a alternativa entre memória e esquecimento, isso ocorre, sem dúvida, porque nem tudo que é memorizável é memorável" (grifo nosso) (CANDAU, 2011, p. 94).

Augusto Artur António da Silva - de Guiné-Bissau, também selecionado pela PEC-G de 1978, cursou Engenharia de Pesca na Universidade Federal Rural de Pernambuco (UFRPE), foi Ministro da Educação Nacional, Cultura, Ciência, Juventude e dos Desportos, de maio de 2009 a abril de 2012, e Ministro dos Negócios Estrangeiros, Cooperação Internacional e das Comunidades de outubro de 2015 a maio de 2016.

Augusto começa o seu relato de vida agradecendo ao Brasil por tudo o que ele tem como carreira profissional na Guiné-Bissau e, logo em seguida, destaca dois fatos que descreve com características negativas, mas que no final sempre fala que todas experiências foram boas e que tiveram seu lado positivo:

A minha experiência no Brasil foi bastante positiva, e, talvez as coisas que eu possa contar, as primeiras perspectivas, foi o fator da lingua, apesar de estar na lingua portuguesa, havia uma diferença bastante grande de alguns significados, me lembro dos colegas, na casa dos estudantes de onde eu morava, quando eu li o primeiro jornal da GuinéBissau [...], em que diria assim no jornal: 'iniciaram as matriculas sem as bichas', então os outros começaram a gozar, e eu não tinha como saber qual era o significado de bicha. A outra vez foi quando fomos a um restaurante [...] fui em um almoço com os colegas e nós não sabiamos o que era o significado de frango, então foi uma experiência bastante negativa, da palavra semântica, e como pensar que uma palavra na Guiné era a mesma coisa no Brasil? Então o senhor que nos atendeu ficou muito aborrecido conosco, foi uma confusão no restaurante e felizmente o dono do restaurante era português $e$ acabou por nos dizer 'Oh, na nossa terra se diz frango, mas aqui se diz galeto' (?). Então mantemos depois uma relação muito boa com o garçom e cada vez que a gente ia lá para o restaurante, sempre que a gente ia lá para comer, ele dizia 'olha, sai dois frangos para os rapazes da Guiné.' São essas experiências que eu tive no Ocidente... Então, posso dizer que, a Universidade Federal de Pernambuco me deu muita coisa positiva [...] (SILVA, 2017 - Divisão de Temas Educacionais).

Na narrativa de Augusto, ele narra a impressão dos fatos que trouxeram à sua memória uma experiência negativa, mas, ao final da narração desses fatos, estes são diluídos em alguma memória a respeito de uma experiência positiva, ou a uma palavra de agradecimento. Augusto sempre tem uma palavra de agradecimento em relação ao Brasil, seja à universidade, aos professores ou à sua formação. Ao final do vídeo, ele narra outra experiência negativa, mas ao final minimiza a experiência com uma palavra de agradecimento: 
O importante daquela época foi que pensaram que o português de Portugal podia ser sempre usado. Me lembro muito bem da primeira prova da zoologia, que o professor me deu uma nota bastante negativa, apesar de ter acertado, disse-me que não, porque não era português do Brasil, portanto tinha que aprender o português do Brasil e não o português de Portugal, portanto foi uma experiência bastante positiva, e que boje eu digo: 'obrigado'[...] (SILVA, 2017 - Divisão de Temas Educacionais).

Augusto sofre uma violência simbólica significativa (BOURDIEU, 2011), isto é, ele foi coagido através de uma imposição cultural, por meio do processo de socialização, a se posicionar no espaço social seguindo critérios e padrões da língua dominante - o português brasileiro. O idioma, no caso, foi o instrumento usado para acometimento dessa violência. Mesmo diante da violência simbólica sofrida, o narrador se posiciona positivamente de modo a "exaltar" essas memórias para que elas recebam um tratamento e uma caracterização positiva na remodelação da narrativa.

Como dito anteriormente, para ter controle sobre as hierarquias das memórias e a caracterização que se faz delas em determinada situação, CANDAU (2011, p. 71) afirma que a memória que se vê nas narrativas de vida coloca em evidência essa aptidão humana que consiste em dominar o próprio passado para esmiuçar " não o vivido, mas o que fica ou ficará do vivido" (grifo nosso). O narrador coloca em ordem e torna coerente os acontecimentos de sua vida que ele julga significativos no momento da narrativa. Os elementos usados para estruturar a construção do enredo da memória, sejam memórias de experiências positivas ou negativas, ilustram as estratégias identitárias que operam em toda a narrativa. Na narrativa de Augusto, descreve três experiências que classifica como negativas, mas, sempre ao final de cada um desses fatos, ele costura essa narrativa à formação universitária que foi adquirido na universidade brasileira e ao sucesso de sua carreira profissional. A narrativa dos fatos não é contada com um “ar” de negação, ao contrário: apesar da caracterização das experiências como negativas, a narração é descrita em meio a risos e minimizando o teor desagradável dessas memórias. Portanto, a memória é remodelada para compor a construção do "eu” profissional, já que esse "eu” é exaltado durante a narração dessa trajetória de vida.

José Maria Neves - cursou Administração de Empresas em São Paulo na Fundação Getúlio Vargas (FGV) e é ex-Primeiro Ministro de Cabo Verde, tendo sido selecionado pela PEC-G de 1980. José Maria começa seu relato ovacionando a experiência que teve no Brasil como a melhor coisa que aconteceu na vida dele: 
A melhor coisa que aconteceu na minha vida foi ter ido estudar no Brasil, fazer Administração Pública numa escola de negócios e governação, é a Escola de Administração de Empresas de São Paulo da Fundação Getúlio V argas, onde aprendi imensamente, tudo o que en sei hoje sobre a liderança, sobre a governação, sobre politicas públicas, sobre desenvolvimento sustentável, aprendi na Fundação Getúlio V argas, foi uma escola cintilante para mim, mas o Brasil também. O Brasil é riquíssimo com aquela diversidade cultural, a possibilidade de termos acessos a livrarias, a um livro cientifico, on a um romance, a música brasileira, finalmente o Brasil tem os apóstrofos da música do mundo, eu acho que... tem uma riqueza enorme. Depois o teatro, as novelas, o sambão, tudo foi uma grande descoberta. E foi um processo de enriquecimento na escola, nas ruas, nos teatros, nos cinemas. A convivencia com aquela riqueza cultural, a politica econômica foi algo extraordinário para mim. Depois, também a riqueza política, estávamos no fim da ditadura militar, na altura da campanha para as Diretas Já', e a transição para a democracia; as primeiras eleições para governadores dos Estados. Então foi um momento muito rico [...]. E tudo que eu vinha a fazer em Cabo Verde depois da minha chegada tem a ver com essa vivência extraordinária no Brasil (NEVES, 2017 - Divisão de Temas Educacionais).

A respeito dessa narrativa, pode-se elucidar o que diz CANDAU (2011, p. 74) que o fato de compor sua trajetória de vida com determinada coerência satisfaz uma apreensão que podemos qualificar como atraente, permite ao narrador transformar a narrativa de si próprio em uma "bela história, que consiga transmitir uma ideia de uma vida completa e rica em experiências de toda a natureza" (grifo nosso). No caso de José Maria, foi narrada uma experiência de imigração passageira repleta de experiências culturais riquíssimas. Nesse sentido, “todo individuo que recorda domestica o passado e, sobretudo, dele se apropria, incorpora e coloca sua marca em uma espécie de selo memorial que atua como significante da identidade" (grifo nosso) (Candau, 2011: 74).

José Maria narra que os jovens que eram enviados ao Brasil para estudar, interpretavam essa missão como um castigo, em seu relato ele não explica o porquê de isso ser visto como um castigo, mas ao se depararem com a realidade brasileira e a identificação com culturas diferentes, avaliaram positivamente suas experiências:

Na nossa caminhada rumo ao Brasil, muitos considerados que estavam a ser castigados porque iam estudar no Brasil, e nós quando chegamos lá, descobrimos um novo mundo, uma realidade muito mais próxima a nós. O sistema de ensino muito mais inovador, enriquecedor, que valoriza e valoriza as competências e uma relação muito mais intensa e de proximidade com os professores. Eu tinha começado a fazer direito em Coimbra, e os meus professores, os professores catedráticos, no um ano em que estive em Coimbra nunca consegui falar com eles, as aulas eram em um grande anfiteatro, duzentos e cinquenta alunos. E quando cheguei à Fundação Getúlio Vargas [...] que era uma escola de elite, entro lá dentro e temos uma sala com cinquenta pessoas, um mestre cortês, como dizemos lá, muito próximo, vinha falar conosco. É uma outra relação, muito mais intensa e foi para nós todos uma experiência completamente diferente, lembro-me de colegas meus que estavam a fazer medicina, a dizer que estavam a aprender muito 
porque o ensino era muito mais prático, muito mais próximo das doenças, a natureza das doenças eram muito mais idênticas a de Cabo Verde, então o Brasil para nós era tudo o que nós podiamos querer para um jovem adolescente que queria a continuar a estudar porque era uma realidade muito mais próxima à realidade cabo verdiana (NEVES, 2017 - Divisão de Temas Educacionais).

O modo como José Maria narra a sua experiência internacional e a ovaciona como estudante intercambistas, nos introduz a uma narrativa avaliativa, como já foi dito anteriormente, de um sujeito que remodela suas memórias a fim de projetar uma boa impressão de si e sobre a experiência vivida. O sujeito minimiza as memórias que classifica como ruins, busca um elo com as narrativas do passado vivido e o costura ao resultado da experiência de vida no tempo presente. José Maria emoldura sua trajetória e elucida que foi a melhor experiência que ele teve em sua vida.

\section{Considerações finais}

Essa pesquisa se limitou a alguns relatos de ex-alunos PEC-G que foram encontradas no portal do Programa. O que foi analisado nas respectivas narrativas diz respeito como são selecionadas determinadas memórias para elucidar a narrativa daquele momento: a narrativa foi construída sempre costurando o passado distante com o "eu" presente. Foi observado em todo arsenal de palavras e nas estruturas das frases, quais foram detalhadamente escolhidas e construídas para narrar uma história de vida baseada em uma ascensão profissional. O que não serve para abrilhantar o presente com as referências do passado é ocultado, e as memórias do passado, que naquele momento foram tidas como memórias não tão agradáveis, são transformadas numa narrativa que trata o fato com vistas a uma conclusão positiva. A imagem que um indivíduo deseja transmitir sobre sí mesmo por meio de elementos do passado é sempre um olhar pré construído de como um sujeito se enxerga no momento que se invoca tais memórias, essas servem para validar a situação presente a fim de que se possa fundar uma imagem satisfatória de sí mesmo, "o fato de dotar de coerência sua trajetória de vida satisfaz uma preocupação que podemos qualificar como estética: permite ao narrador transformar aos seus próprios olhos a narrativa de si próprio em uma bela história..." (grifo nosso) (CANDAU, 2011, p. 74).

Usando as teorias de Candau e Rosenthal como fundamento referencial, conclui-se que é através das memórias e como as interpretamos foi como a identidade destes ex- 
estudantes puderam ser modeladas. É através das memórias selecionadas, ocultadas, omitidas, ou reinventadas que reconstruímos tais narrativas para relatar, por exemplo, trajetórias de vida. Podemos observar, nos relatos dos ex-alunos, como eles se veem após mais de trinta ou quarenta anos de uma experiência que marcou significativamente a vida de cada um, segundo seus respectivos relatos. A narração da trajetória de vida de cada um foi marcada por uma ascensão profissional, isso diz muito sobre como eles narram positivamente essa experiência de vida, em alguns casos, um olhar positivo só é possível após anos de reflexão e acontecimentos. Ao olharem para suas vidas atuais fazendo referência ao passado eles enxergam essas memórias como algo benéfico, que lhes trouxe importantes conquistas.

\section{Referências}

\section{Depoimentos analisados}

Ana Emília de Barros Sá. Depoimento PEC-G - Guiné-Bissau. 2017 (19min58s). Disponível em http://www.dce.mr e.gov.br/PEC/G/depoimen-

tos_PT.php - Último acesso em: 24/05/2020

Augusto Artur Antonio da Silva. Depoimento PEC-G - Guiné-Bissau: . 2017 (6min09s). Disponível em: http://www.dce.mre.gov.br/PEC/G/de poimentos_PT.php - Último acesso em: 24/05/2020

José Maria Neves. Depoimento PEC-G Cabo Verde. 2017 (4min14s). Disponível em:

http://www.dce.mre.gov.br/PEC/G/de poimentos_PT.php - Último acesso em: 24/05/2020

\section{Referências bibliográficas}

BOURDIEU, Pierre. "A escola conservadora: as desigualdades frente à escola e à cultura". In: Escritos de Educação.
Petrópolis, Vozes, 2011.

BRAH, Avtar. "Diáspora, fronteras e identidades transnacionales". In: Cartografías de la diáspora: identidades em cuestión. Madrid: Traficantes de Sueños, 2011, p. 209-242.

BRASIL. Decreto Presidencial no 7948 , 12 de março de 2013. Disponível em: http:/ /www.planalto.gov.br/CCIVIL_03/_Ato2011-2014/2013/Decreto/D7948.htm.

BRASIL. Ministério das Relações Exteriores - Divisão de Temas Educacionais Apresentação em: http://www.dce.mre.gov.br/PEC/PEC G.php.

BRASIL. Portal MEC - Programa de Estudantes-Convênio de Graduação - PECG Disponível em: http://portal.mec.gov.br/index.php?option $=$ com_content\&view $=$ article\&id $=12276 \&$ Itemid $=531$.

BRUNER, Jerome. "Por que, então, 
narrativas?" In: Fabricando Histórias: Direito, Literatura, Vida. São Paulo: Letra e Voz, 2014.

CANDAU, Joël. Memória e Identidade. São Paulo: Editora Contexto, 2011.

GUSMÃO, Neusa Maria Mendes. "Africanos no Brasil: imigrantes, refugiados e estudantes." In: Diáspora Africana e migração na era da globalização: experiências de refúgio, estudo e trabalho. Curitiba: CRV, 2015.

- "Apresentação". In: Revista Pro-Posições, Campinas, v. 20, n. 1 (58), p. 13-21, jan./abr., 2009.

HALL, Stuart. A identidade cultural na pós-modernidade. Rio de Janeiro: Lamparina, 1992.

HIRSCH, Olivia Nogueira. "'A gente parece um camaleão': (re)construções identitárias em um grupo de estudantes caboverdianos no Rio de Janeiro”. In: Revista Pro-Posições. Campinas, v. 20, n. 1 (58), p. 65-81, jan./abr., 2009. Disponível em: http://www.scielo.br/pdf/pp/v20n1/v20n1a05.pdf.

LANGA, Ercílio Neves Brandão. Diáspora africana no Ceará no século XXI: ressignificações identitárias de estudantes imigrantes. 2016. 563 f. Tese (Doutorado) - Curso de Sociologia, Universidade Federal do Ceará, Fortaleza, 2016. Disponível em: http://www.repositorio.ufc.br/handle/riufc/21801.

MALOMALO, Bas'llele. VARGEM, Alex Andre. "A imigração africana contemporânea para o Brasill”. In: Diáspora Africana e migração na era da globalização. Curitiba: CRV, 2015.
MORAIS, Sara. SILVA, Kelly. "Tendências e tensões de sociabilidade de estudantes dos Palop em duas universidades brasileiras". In: Revista Pro-Posições, Campinas, vol 23, nº1, jan/abr. 2012. Disponível em:

http://www.scielo.br/scielo.php?script=sci_arttext\&pid=S010373072012000100011\&lang $=$ pt

MOURÃO, Daniele Ellery. - África "na pasajen" identidades e nacionalidades guineenses e cabo-verdianas. 2006. Dissertação (Mestrado) - Programa de Pós-Graduação em Sociologia, Universidade Federal do Ceará, Fortaleza, 2006.

NORA, Pierre. "Entre memória e história: a problemática dos lugares". In: Revista PUC-SP, São Paulo, vol. 10, 1993. Disponível em:

https://revistas.pucsp.br/index.php/revph/article/viewFile/12101/8763.

ROSENTHAL, Gabriele. "História de vida vivenciada e história de vida narrada: a interrelação entre experiência, recordar e narrar". In: Revista Civitas, Porto Alegre, v. 14, n. 2, p. 227-249, maio-ago. 2014. Disponível em: http://revistaseletronicas.pucrs.br/ojs/index.php/civitas/article/view/17116.

SAYAD, Abdelmalek. O que é um imigrante?: Imigração ou os paradoxos da alteridade. São Paulo: EDUSP, 1998.

SUBUHANA, Carlos. "A experiência sociocultural de universitários da África lusófona no Brasil: entremeando histórias". In: Revista Pro-Posições, Campinas, vol.20, n.1, 2009, pp.103-126.

Disponível em: http://www.scielo.br/pdf/pp/v20n1/v20n1a07.pdf. 
VERTOVEC, Steven. "Concebendo e pesquisando o transnacionalismo". In:
Press, Ethnic and Racial Studies, Vol. 22, No. 2,1999 